\title{
Simplification of simulation processes at gravity heat pipes
}

\author{
Peter Hrabovský ${ }^{1, a}$, Štefan Papučík ${ }^{1}$, Richard. Lenhard ${ }^{1}$ \\ ${ }^{1}$ Department of Energy Technology, Faculty of Mechanical Engineering, University of Zilina, Slovakia
}

\begin{abstract}
Water heating by heat pipe is currently the object examined on the use in sphere of recovering heat from technological processes. The heat pipe is the device for water heating that provides us a very effective way of transferring heat from the heat source (combustion) to the place of consumption (water). For the draft proposal of such equipment is produced under the required conditions mathematical model of ANSYS that verifies the actual measurements the experiments. The paper deals with the possibility of simulations of heat pipes in the process of heat transport and apposite simplification of the simulation process by defining apposite the substitutes of the solid materials with its own thermal properties that ensure a similar heat transport as a heat transfer medium in the heat pipe.
\end{abstract}

\section{Introduction}

Heat pipes are now mainly used in refrigeration engineering, to remove heat from electrical components. They can be found mainly in computing, which is mounted on the processor (CPU, GPU, chipset ...) from which dissipates heat through active or passive cooler. The heat pipes are mainly used in the industry where it is necessary to comply with dust-proof, air tightness, water tightness. From such a closed space can removed heat by heat pipes [1].

Heat pipes are used in solar system for heating and heat transfer with heat exchangers. Heat pipes are devices that transfer heat efficiently. They can be used to transfer heat from the source at a higher energy potential for example built-in fireplaces in the home [2]. Of these, it is possible to capture the radiant heat component, which can be used for hot water or heating other rooms.

The aim of this experiment is to create a material that will serve as a substitute for the heat pipe. This material simplifies the mathematical models of CFD simulation, in which the problem is to define the overall heat transfer of heat pipe, respectively the actions that are going in the heat pipe. For example boiling, condensation, heat transfer.

\section{Characteristic of solid material}

The most commonly used electrical and thermal conductor is copper. We can find it in the electrical installation, heating cables, heating and cooling systems. In refrigeration engineering, is used in heat exchangers, which transfers heat to the ambient.
Heating systems used copper pipes and heat exchangers that allow the exchange and transport of heat. Given its price and availability are replaced by other materials, for example stainless steel and plastic.

In this experiment, we used a full copper pipe, figure 1 , with a diameter of $18 \mathrm{~mm}$ and length $400 \mathrm{~mm}$.

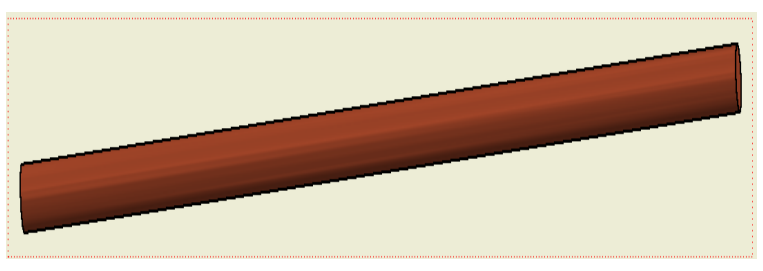

Figure 1. Model of full copper pipe

\section{Characteristic of heat pipe}

We used a heat pipe to transfer heat from the heat source to the point of consumption of heat with high efficiency and low temperature difference. It is a sealed device in which the net substance (water) exist in the liquid and the gas phase at a pressure below atmospheric pressure (vacuum). Cleanliness of the working fluid is an important parameter for the efficiency of the heat pipe, in terms of heat transfer [3, 4 and 5]. The actual heat pipe, figure 2, consists of evaporation, condensation, and the adiabatic section. In the evaporator the working fluid is evaporated at a temperature below normal conditions. In the adiabatic section is not exchanged heat transfer through the ambient area, due to the isolation of a few working fluid to the wall of the heat pipe condensation film of condensed working fluid. In the condenser the vapor of working fluid condenses on the walls of the heat pipe,

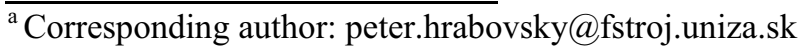


which transmit latent (condensing) heat through the walls of the heat pipe to the heat consumption point [6].

Filling of the heat pipe in this experiment is the distilled water. The production process of the heat pipe consists of the preparation of the material, the soldering of components, filling the working fluid and its evaporation to required volume. The final volume of the working fluid is about $20 \%$ of the total volume of the heat pipe, which is about $16 \mathrm{ml}$ of water. This volume has been established on the basis of previous experiments that compared the effectiveness of the heat pipe at various percentages volumes of the working fluid. The value $20 \%$ of the working fluid in the heat pipe reached the best results. The diameter of the heat pipe is $18 \mathrm{~mm}$ and length $400 \mathrm{~mm}$.

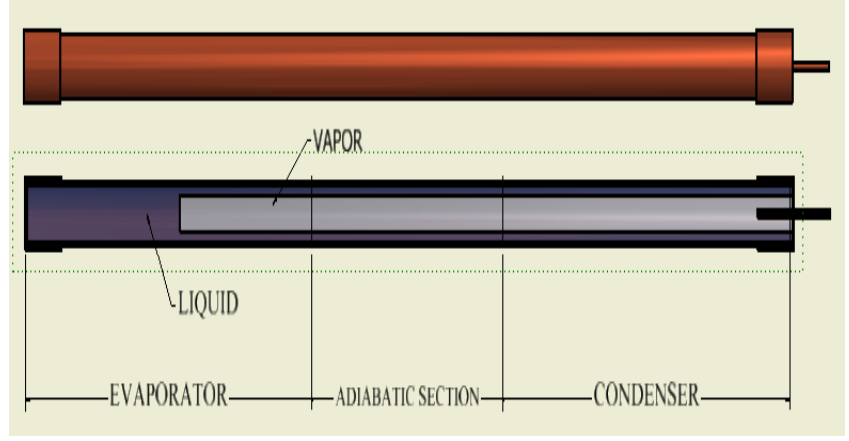

Figure 2. Model of heat pipe

\section{Characteristic of test device}

Device of experiment consists of two parts (cases), on which the fixed the full copper pipe or the heat pipe. In figure 3 is shown the experimental device.

A case situated in the upper part, (figure $4 b$, reference 3 ) is the part of a cooling device. It is connect to the cooling device, the cooling medium is water. The water circulates in a closed circuit between the cooling device and the case. In the cooling circuit included the safe cases, in which there are devices for measuring the temperature at entry and exit of water. In the circuit is included flow meter too that shows speed of flow of the refrigerant in a closed circuit. A case situated at the bottom part (Figure $4 \mathrm{~b}$ ref. 2) is the heating of the device. It is connected to the heating device, the working medium is water. In a closed heater circuit included thermocouples for temperature measurement inlet and outlet water from the case, flow meter for flow measurement.. The circuit contents a valves that get disconnect the heater case when it is need for cooling with cold water, while avoiding the cooling of heating up the water in the heater circuit. Measured samples are mounted in the cases by caulked joints with seals, which are not being relaxed, possible leakage of cooling or heating of the working fluid.

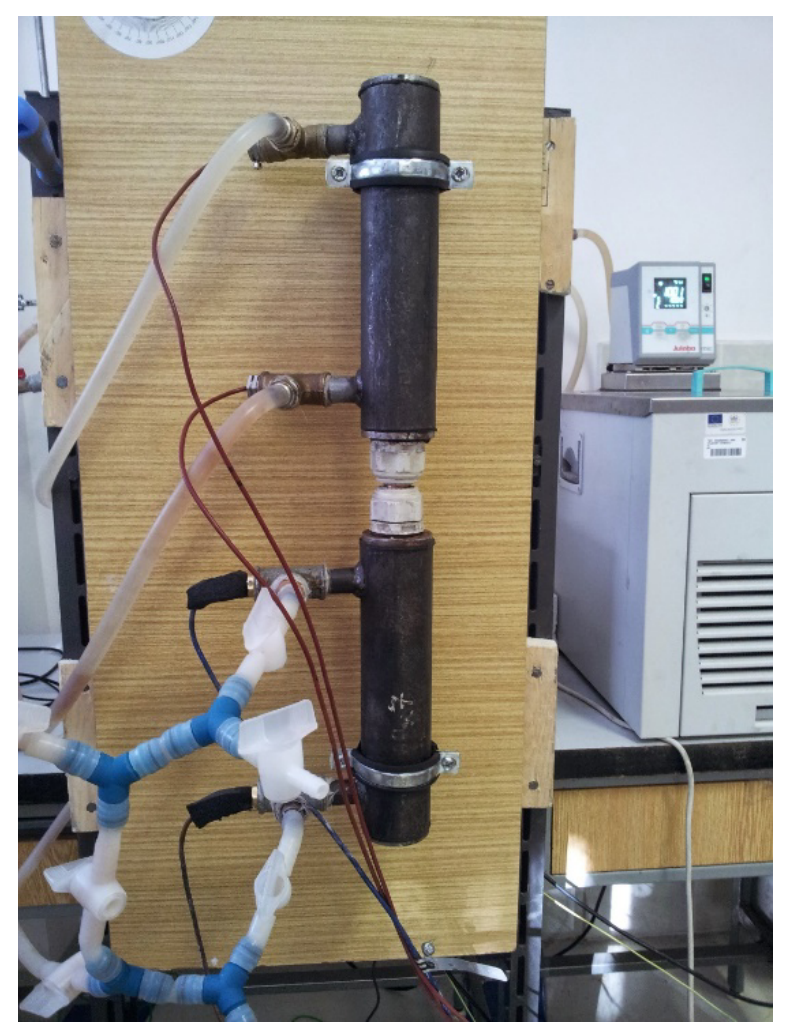

Figure 3 Real view on the experimental device

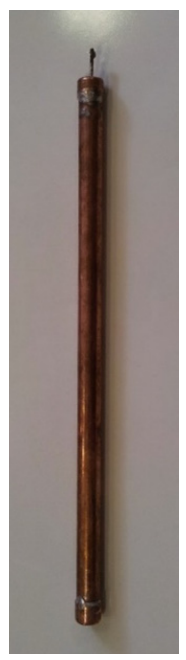

a)

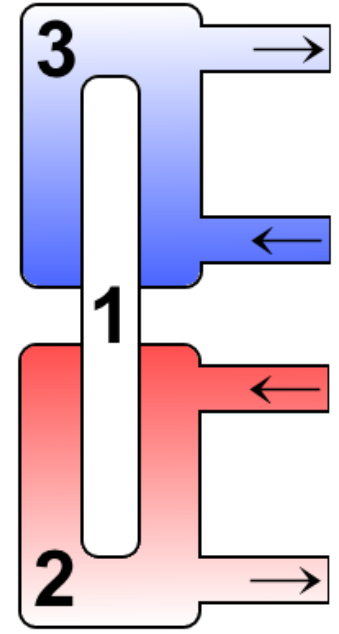

b)

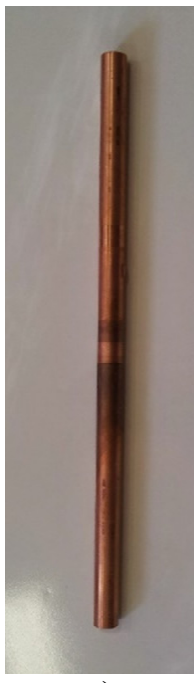

c)
Figure 4. a) heat pipe, b) scheme of experimental device, c) copper bar

\section{Experiment}

Experiment came through in normal conditions at $20{ }^{\circ} \mathrm{C}$. As the first sample was measured by a full copper pipe. The cooling circuit was set to $10^{\circ} \mathrm{C}$ at a flow rate of $1.72 \mathrm{dm}^{3} \mathrm{~min}^{-1}$. The heating circuit was set to $80^{\circ} \mathrm{C}$ at a flow rate of $4.79 \mathrm{dm}^{3} \cdot \mathrm{min}^{-1}$.

In Figure 65 we can see total progress of heat transfer at the full copper pipe. Equilibrium of heat transfer achieved in $500 \mathrm{~s}$. The subsequent recording of data was found average performance $61.9 \mathrm{~W}$. 
After that came through the measurement of the heat pipe under the same conditions as the full copper pipe. The cooling circuit was set to $10{ }^{\circ} \mathrm{C}$ at a flow rate of $1.72 \mathrm{dm}^{3} \mathrm{~min}^{-1}$. The heating circuit was set to $80^{\circ} \mathrm{C}$ at a flow rate of $4.79 \mathrm{dm}^{3} \mathrm{~min}^{-1}$.

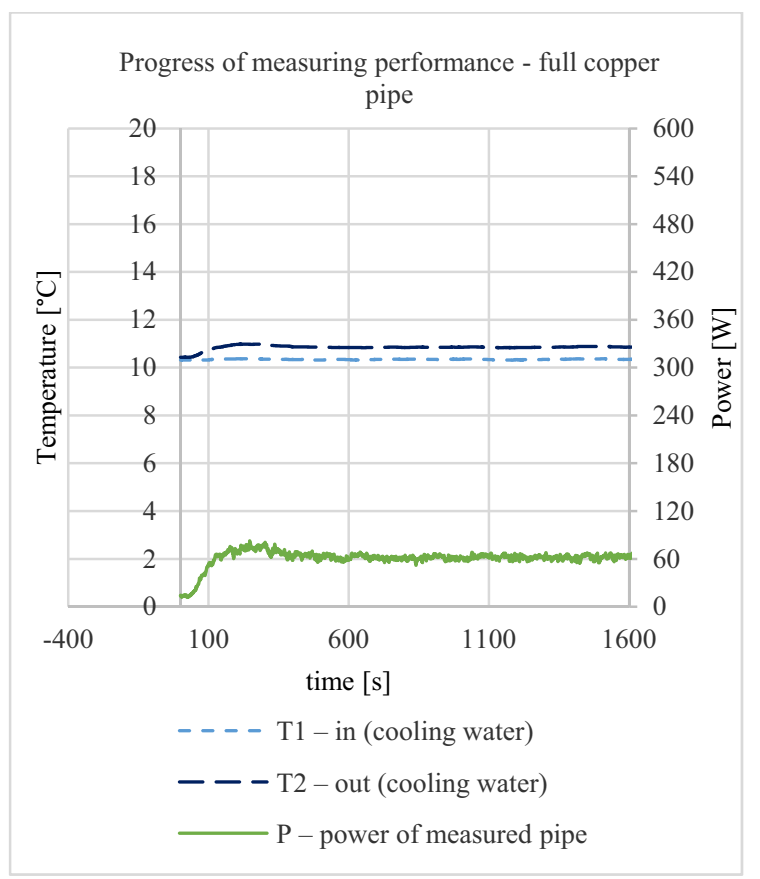

Figure 5. Graph result of full copper pipe

In Figure 6 we can see total progress of heat transfer at the heat pipe. Equilibrium of heat transfer achieved in $500 \mathrm{~s}$. The subsequent recording of data was found average performance $516.1 \mathrm{~W}$.

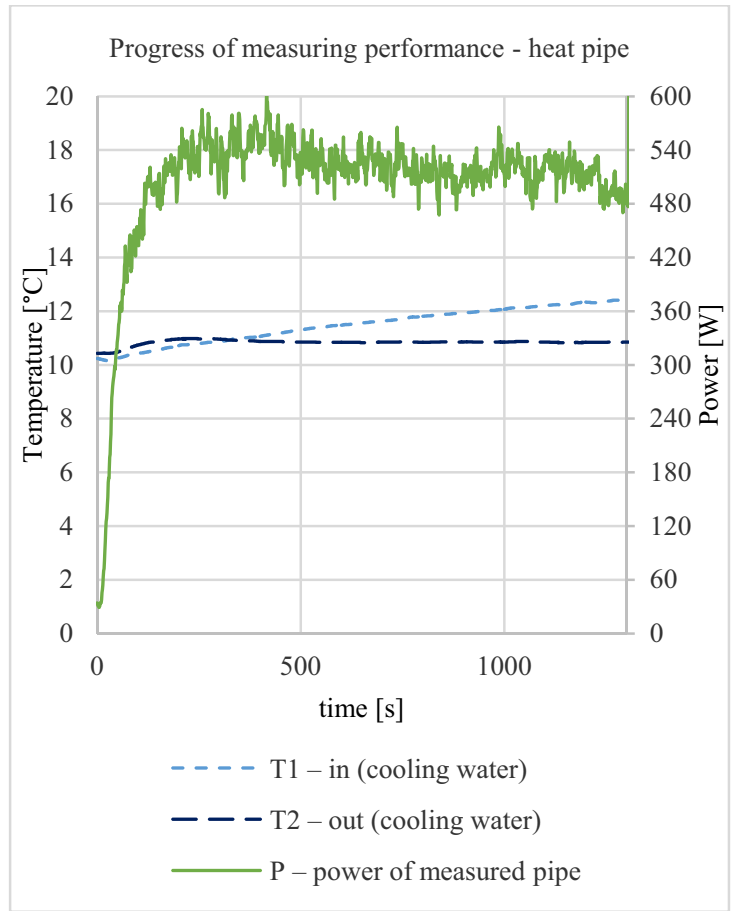

Figure 6. Graph result of heat pipe

\section{CFD simulation}

CFD simulation uses pc hardver to gain the results from thermodynamics systems. The CFD results we can use to comparing with real model of system. The experiment was carried out in a mathematical simulation of CFD ANSYS. The resulting mesh in Figure 7 is a simplified model of polyhedral and has parameters 239302 cells, 1552487 faces, 1306224 nodes.

Individual volumes created appear cold water, hot water, copper rod, heat pipes filled with water-vapor its thermal conductivity value was choose from set of numbers $(500,1000,2500,5000,10000,15000,20000$, $25000,30000,40000,45000,50000)$, the numbers of set are value of thermal conduction and unit is $\mathrm{W} \mathrm{m}^{-1} \mathrm{~K}^{-}$ 1 .

Boundary conditions are the same as physical experiments (entered from physical experiment) energy on, laminar flow - revealed by the Re $\mathrm{f}(\mathrm{v}, \mathrm{d})$, time-independent model. In figure $7 \mathrm{left}$, the bottom part is an evaporator and the upper part is a condensation.

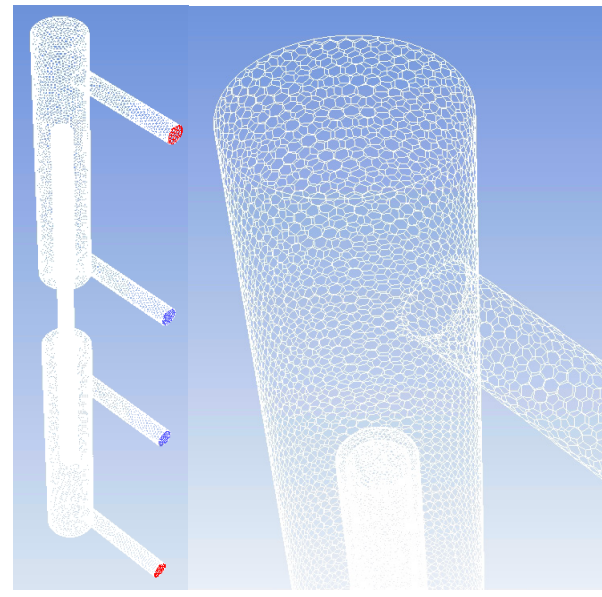

Figure 7. Mesh of CFD model

Input parameters of cooling water - temperature $10{ }^{\circ} \mathrm{C}$, the mass flow rate $0.0287 \mathrm{~kg} \mathrm{~s}^{-1}$. The outlet of cooling water was determined with parameter outflow. Input parameters of heater - temperature $80^{\circ} \mathrm{C}$, the mass flow rate $0.0781 \mathrm{~kg} \mathrm{~s}^{-1}$. The outlet of the heating water was determined with parameter outflow. 
Table 1 Result of simulation of heat pipe

\begin{tabular}{|c|c|c|c|c|}
\hline $\begin{array}{c}\text { Thermal } \\
\text { coductivity }\end{array}$ & $\begin{array}{c}\text { In cold } \\
\text { water }\end{array}$ & $\begin{array}{c}\text { Out cold } \\
\text { water }\end{array}$ & $\begin{array}{c}\text { Heat } \\
\text { capacity }\end{array}$ & Power \\
\hline $\mathrm{W} \mathrm{m}^{-1} \mathrm{~K}^{-1}$ & $\mathrm{~K}$ & $\mathrm{~K}$ & $\mathrm{~J} \mathrm{~kg}^{-1} \mathrm{~K}^{-1}$ & $\mathrm{~W}$ \\
\hline 500 & 283.15 & 283.42 & 4197.62 & 32.92 \\
\hline 2500 & 283.15 & 284.30 & 4197.15 & 138.52 \\
\hline 5000 & 283.15 & 284.96 & 4196.80 & 217.71 \\
\hline 10000 & 283.15 & 285.75 & 4196.39 & 313.40 \\
\hline 15000 & 283.15 & 286.22 & 4196.14 & 369.55 \\
\hline 20000 & 283.15 & 286.53 & 4195.98 & 406.78 \\
\hline 25000 & 283.15 & 286.74 & 4195.87 & 433.04 \\
\hline 30000 & 283.15 & 286.90 & 4195.79 & 451.71 \\
\hline 40000 & 283.15 & 287.07 & 4195.70 & 472.79 \\
\hline 45000 & 283.15 & 287.10 & 4195.68 & 476.53 \\
\hline 50000 & 283.15 & 287.14 & 4195.67 & 480.26 \\
\hline
\end{tabular}

The results of simulation of heat pipe are shown in the picture Figure 8 . We can see, that the result of simulation are similarly as the result of physical model. When we use the water-vapor as the working fluid of heat pipe, the result of simulation are approaching to the result of physical model. We had changed one property of water-vapor, which is thermal conductivity.

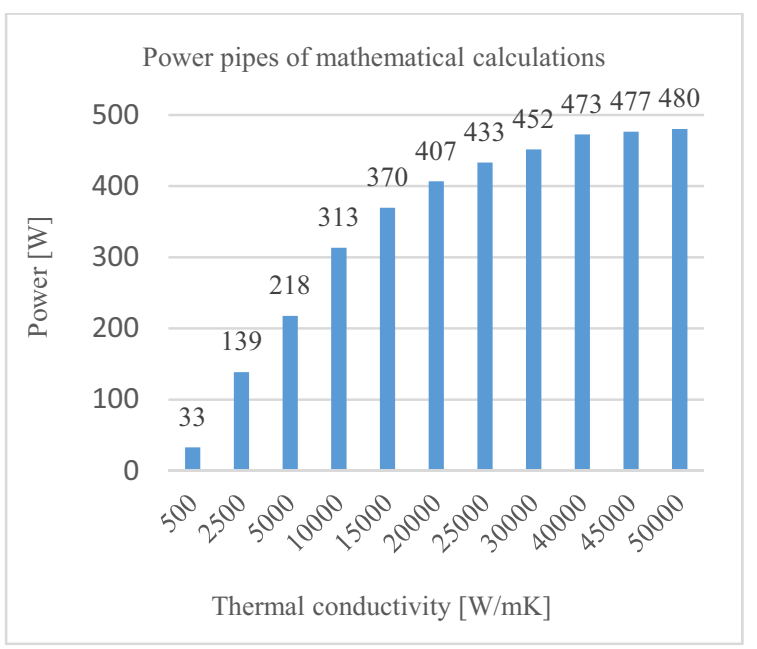

Figure 8. Depend the power of thermal conductivity

In Figure 9 we can see progress of water-vapor, which has changeable property of thermal conductivity. Efficiency of heat transfer is directly depending on the value of thermal conductivity.

In Table 1 are value of thermal conductivity, temperature of cooling water (in, out), heat capacity at temperature outer cooling water and power that the new material transferred in form of heat.

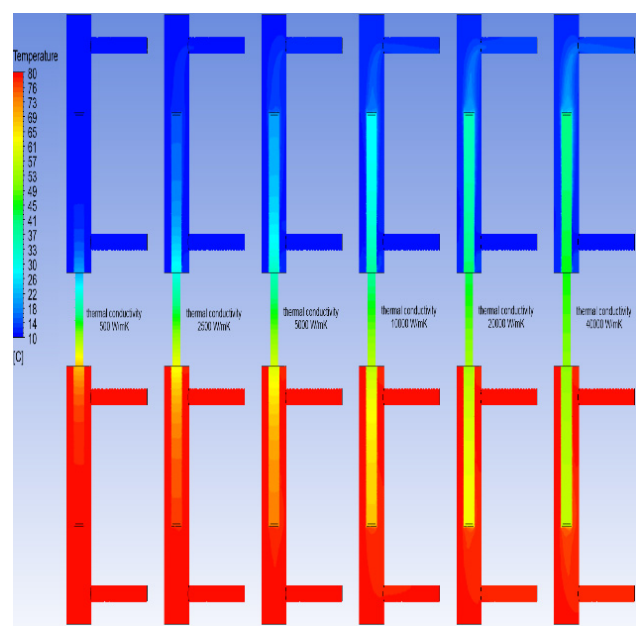

Figure 9. Heat transfer at various values of thermal conductivity

\section{Conclusion}

This model was computed as steady model. This model shown new material that is similarly as water-vapor. The changing is on one property now, which is thermal conductivity. Actually is in progress transient model that is depend of time. New model can show new results of progress from field of heat transfer.

\section{Acknowledgment}

This article was elaborated within the solution of project KEGA č.029ŽU-4/2015 „Recovering heat from technological processes“".

\section{References}

1. M. Kasanicky, S. Gavlas, M. Vantuch, M. Malcho, Possibilities of using Carbon Dioxide as Fillers for Heat Pipe to Obtain Low-potential Geothermal Energy. Experimental fluid mechanics, 2012, p. 332-336, ISBN 978-80-7372-417-7

2. M. Patsch, J. Labaj, Influence of Glycerin Combustion in Experimental Burner on Production of Emissions. Acta metallurgica slovaca conference. ISSN 1338-1660

3. P. Nemec, A. Caja, Heat Transfer Intensification Applying Thermal Tubes, Acta Metallurgica Slovaca, 2009, vol. 15, No. 1, pp. 215-220.

4. P. Nemec, A. Caja, Heat Transport Visualization of Heat Pipe by Thermovision, Experimental fluid mechanics, 2010, ISBN 978-80-7372-670-6, pp. 431-434.

5. P. Nemec, Influence Heat Transfer Limitations of Heat Pipes on their Cooling Power, Transcom, 2009, ISBN 978-80-554-0031-0, pp. 103-108.

6. P. Nemec, M. Malcho, M. Smitka, J. Matusov, Perofrmance Parameters of Clodes Loop Thermosyphon. Communications - Scientific Letters of the University of Zilina, vol. 14, No. 4a, 2012, pp. 53-57, ISSN 1335-4205. 